\title{
RELAÇÕES ENTRE A BNCC E O DIREITO DE BRINCAR NA EDUCAÇÃO INFANTIL
}

\section{RELATIONS BETWEEN BNCC AND THE RIGHT TO PLAY IN EARLY CHILDHOOD EDUCATION}

\author{
Andreia de Bem Machado', Vera Regina Lúcio²
}

\begin{abstract}
Submetido em: 09/05/2020
Revisões requeridas em: 14/06/2021

Aprovado em: 14/09/2021

\section{RESUMO}

No mundo globalizado, a partir da Lei de Diretrizes e Bases, iniciou-se as discussões e políticas da educação infantil, pois essa passa a ser parte integrante da educação básica. As questões referentes a um currículo nacional passam a ser implementadas no cenário nacional a partir da Base Nacional Comum Curricular (BNCC), para posteriormente serem discutidas nos estados e municípios. Sendo assim, o objetivo deste trabalho será identificar as relações entre a BNCC e o direito de brincar na educação infantil. Para tanto utilizou-se da metodologia bibliográfica e documental. Os resultados alcançados vislumbram um olhar diferenciado para o planejamento. Esse deverá ter a brincadeira e a interação que são os eixos base e que qualificam as ações da prática docente.
\end{abstract}

PALAVRAS-CHAVE: Educação Infantil. BNCC. Brincar.

\section{ABSTRACT}

In the globalized world, from the Law of Directives and Bases, discussions and policies on early childhood education began, as this becomes an integral part of basic education. Issues relating to a national curriculum are now implemented on the national scene from the Common National Curriculum Base (BNCC), to be later discussed in the states and municipalities. Therefore, the objective of this work will be to identify the relationships between the BNCC and its relationship with the right to play in early childhood education. For this purpose, bibliographic and documentary methodology was used. The results achieved provide a differentiated look at planning. This should have the play and interaction that are the basic axes and qualify the actions of teaching practice.

\section{KEYWORDS: Early Childhood Education. BNCC. Official documents.}

\footnotetext{
1 Doutora no Programa de Pós-Graduação em Engenharia e Gestão do Conhecimento (PPEGC) na Universidade Federal de Santa Catarina (UFSC). Mestre em Educação Científica e Tecnológica (PPGECT) na Universidade Federal de Santa Catarina (UFSC). Especialista em Alfabetização na Universidade do Estado de Santa Catarina (UDESC). Graduada em Pedagogia na Faculdade de Educação (FAED) na Universidade do Estado de Santa Catarina (UDESC) Experiência na área de Educação há mais de 20 anos e com ênfase em Educação a Distância (EaD) desde de 2004, atuando principalmente nos temas: orientação de trabalho de pós graduação a distância, planejamento, desenvolvimento, coordenação nos cursos a distância. Atualmente desenvolve trabalhos e pesquisas na área de planejamento, prática, acompanhamento e avaliação em EaD, educação corporativa, inovação, habitat de inovação, empreendedorismo, incubadora, parques tecnológicos bem como na área de Mídia e Gestão do Conhecimento. Atua também como professora formadora, palestrante, docente no ensino superior, professora orientadora e avaliadora de artigos científicos. Autora de livro e artigos científicos. andreiadebem@ gmail.com

2 Possui Graduação em Pedagogia pela Universidade do Vale do Itajaí (2006), Graduação em Educação Física - Universidade Federal de Santa Catarina (1980), Mestrado em Educação pela Universidade do Vale do Itajaí (2005) e Doutorado em Educação pela Universidade Tecnológica Intercontinental. UTIC (2018). Atualmente é professora efetiva da Faculdade Municipal de Palhoça e do Centro Universitário Municipal de São José, em ambas instituições no Curso de Pedagogia. Atuando, principalmente, nas áreas da aprendizagem, formação docente, espaço, elementos curriculares, gestão escolar, planejamento, avaliação e estágio (Educação Infantil, Ensino Fundamental, EJA e Gestão) e Orientação de TCC. E-mail: veralucio.educ@gmail.com.
} 


\section{INTRODUÇÃO}

As discussões sobre os temas referentes à Educação Infantil não são recentes, remontam à década de 1980, quando os educadores iniciaram os debates sobre a qualidade da educação pública e explicitaram sobre a importância de um sistema nacional de educação que proporcionasse o acesso e permanência das crianças e dos jovens na Educação Básica e no Ensino Superior.

Assim, os debates transpareceram em legislações para Educação infantil com a Lei de Diretrizes e Bases da Educação (LDB - Lei n 9.394/96) que além da criação de critérios e indicadores para o atendimento em instituições creches e pré-escolas que respeitem os direitos fundamentais das crianças, também legalizaram a Educação Infantil como parte integrante da Educação Básica.

Em 2006, os Parâmetros Nacionais de Qualidade em Educação Infantil e a Política Nacional de Educação Infantil já explicitava acerca do direito das crianças de zero a 6 anos à educação. No mesmo ano, a Lei 11.274/06 altera a redação dos artigos 29, 30, 32 e 87 da LDB, encaminhando diretrizes sobre a duração de nove anos para o Ensino Fundamental, com matrícula obrigatória a partir dos 6 anos de idade. Já em 2010, as Diretrizes Curriculares Nacionais para a Educação Infantil e o documento final da CONAE foram instituídos com o objetivo de expressar as discussões anteriores à publicação do Plano Nacional de Educação 2014 - 2024 (Lei 13.005/14).

No ano de 2014, inicia-se a discussão do Plano Nacional de Educação (PNE), criado pela Lei 13.005/14. Com essa legislação inicia-se o processo de criação da Base Nacional Comum Curricular (BNCC), aprovado no ano de 2017. Com a criação da BNCC, estados e municípios tiveram que readequar seus documentos, com um novo repensar dentro de cada contexto regional as propostas curriculares da educação infantil. Assim, o objetivo desse artigo é identificar as relações entre a BNCC e os documentos oficiais da Educação Infantil que já fazem parte do processo educacional e as que podem vir a ser elaboradas, validadas e operacionalizadas pelos municípios.

O texto foi organizado em quatro secções: essa primeira parte introdutória, a segunda que trata dos pressupostos históricos da BNCC e a educação Infantil, a terceira que explicita sobre o direito de brincar e a quarta que tecemos as considerações finais.

\section{PRESSUPOSTOS HISTÓRICOS DA BNCC E A EDUCAÇÃO INFANTIL}

A educação das crianças até 6 anos tem sido vista, como um investimento primordial para o seu desenvolvimento desde os primeiros meses até a idade de acesso à escolarização obrigatória aos 4 anos, ainda na pré-escola. Porém cabe ressaltar que, essa etapa não representa uma antecipação ou preparo para a escolarização formal que ocorre nos anos iniciais do Ensino Fundamental, haja vista que, a Educação Infantil é uma etapa da Educação Básica (LDB 9394/96) cujo trabalho pedagógico é norteados pelos eixos interações e brincadeiras e em um espaço público que propicia a convivência entre crianças e adultos.

A educação infantil instituída a partir da LDB lei 9394/96, com a oferta do atendimento de crianças em creche (até 3 anos) e pré-escola ( 4 a 6 anos), também é reconhecida como a primeira etapa da Educação Básica e descrita como uma fase de grande importância para a criança por compor as primeiras experiências de ação educativa, externas à família, que ela vivência.

De acordo com o artigo 29 da LDB (1996) a educação infantil tem como objetivo "o desenvolvimento integral da criança até seis anos de idade, em seus aspectos físico, psicológico, intelectual e social, completando a ação da família e da comunidade" (BRASIL, 1996).

Nesse contexto, a educação infantil passa a desempenhar um papel de extrema relevância no desenvolvimento da criança de forma integral e em diferentes tempos, espaços e ações por meio de políticas públicas comprometidas com a organização do currículo. Esse compromisso se explicita e está garantido no art. 26 da LDB, na redação dada pela Lei no 12.796/2013: 
[...] os currículos da educação infantil, do ensino fundamental e do ensino médio devem ter base nacional comum, a ser complementada, em cada sistema de ensino e em cada estabelecimento escolar, por uma parte diversificada, exigida pelas características regionais e locais da sociedade, da cultura, da economia e dos educandos (BRASIL, 2013).

A resolução $\mathrm{CNE} / \mathrm{CP} \mathrm{n}^{\circ}$ 2, de 22 de dezembro de 2017 institui e orienta a implantação da Base Nacional Comum Curricular (BNCC) ao longo das etapas e respectivas modalidades no âmbito da Educação Básica, considerando que:

[...] seu conjunto orgânico e progressivo de aprendizagens essenciais que todos os estudantes da Educação Básica devem desenvolver ao longo das etapas da Educação Infantil e do Ensino Fundamental, efetivamente subsidiem a construção de currículos educacionais desafiadores por parte das instituições escolares, e, quando for o caso, por redes de ensino, comprometidos todos com o zelo pela aprendizagem dos estudantes, republicanamente, sem distinção de qualquer natureza (BRASIL, 2017).

Essa mesma resolução no seu Capítulo IV - Da BNCC no artigo 10, retoma e fortalece o conceito de criança como "sujeito histórico e de direitos, que interage, brinca, imagina, fantasia, deseja, aprende, observa, experimenta, narra, questiona e constrói sentidos sobre a natureza e a sociedade, produzindo cultura" definido pelo Conselho Nacional de Educação na Resolução CNE/CEB 5/2009 ao estabelecer os direitos de aprendizagem e desenvolvimento no âmbito da Educação Infantil:

I. Conviver com outras crianças e adultos, em pequenos e grandes grupos, utilizando diferentes linguagens, ampliando o conhecimento de si e do outro, o respeito em relação à cultura e às diferenças entre as pessoas;

II. Brincar cotidianamente de diversas formas, em diferentes espaços e tempos, com diferentes parceiros (crianças e adultos), ampliando e diversificando seu acesso a produções culturais, seus conhecimentos, sua imaginação, sua criatividade, suas experiências emocionais, corporais, sensoriais, expressivas, cognitivas, sociais e relacionais;

III. Participar ativamente, com adultos e outras crianças, tanto do planejamento da gestão da escola e das atividades, propostas pelo educador quanto da realização das atividades da vida cotidiana, tais como a escolha das brincadeiras, dos materiais e dos ambientes, desenvolvendo diferentes linguagens e elaborando conhecimentos, decidindo e se posicionando em relação a eles;

IV. Explorar movimentos, gestos, sons, formas, texturas, cores, palavras, emoções, transformações, relacionamentos, histórias, objetos, elementos da natureza, na escola e fora dela, ampliando seus saberes sobre a cultura, em suas diversas modalidades: as artes, a escrita, a ciência e a tecnologia;

V. Expressar, como sujeito dialógico, criativo e sensível, suas necessidades, emoções, sentimentos, dúvidas, hipóteses, descobertas, opiniões, questionamentos, por meio de diferentes linguagens;

VI. Conhecer-se e construir sua identidade pessoal, social e cultural, constituindo uma imagem positiva de si e de seus grupos de pertencimento, nas diversas experiências de cuidados, interações, brincadeiras e linguagens vivenciadas na instituição escolar e em seu contexto familiar e comunitário (BRASIL, BNCC, 2017).

Os direitos de aprendizagem e desenvolvimento, conviver, brincar, participar, explorar, expressar e conhecer-se, somente serão garantidos se forem respeitados os grupos etários e se a intencionalidade pedagógica contemplar práxis docente. Essa deve estar estruturada a partir dos campos de experiências e dos objetivos de aprendizagem e desenvolvimento, nessa pesquisa daremos ênfase ao brincar. 


\section{DIREITOS DE APRENDIZAGEM NA EDUCAÇÃO INFANTIL - O BRINCAR}

Na educação infantil, partindo dos eixos estruturantes "interações e brincadeiras", esse "saber e saber fazer" essencial proposto pela BNCC (2018) está definido nos Campos De Experiências (O eu o outro e nós - Traços, sons, cores e formas - Escuta, fala, pensamento e imaginação - Espaços, tempos, quantidades, relações e transformações) respaldados pelas DCNEI por contemplarem conhecimentos e experiências que precisam ser oportunizados às crianças. Por conseguinte, as aprendizagens também se constituem a partir dos comportamentos, das habilidades e das vivências, dessa forma se organizando em Objetivos De Aprendizagem E Desenvolvimento. (grifo das autoras).

Nesse contexto, como explicitado anteriormente, o brincar deve ocorrer de diferentes maneiras, em diferentes espaços e tempos, com diferentes pessoas (adultos e crianças) de maneira a ampliar e diversificar suas possibilidades de promoção a produções culturais. As brincadeiras devem ser proporcionadas, com o objetivo de desenvolver nas crianças, o imaginário, a criatividade, a expressão, e proporcionar maior interação entre elas. Segundo Oliveira (2012, p. 202), "brincar é algo que se aprende em sociedade, o contato com a cultura, por meio do professor e dos recursos que ela apresenta, faz avançar significativamente a qualidade da brincadeira". Sendo assim, o jogo pode desenvolver na criança a habilidade de compreender as regras, conforme a autora, ao jogar, as crianças imitam procedimentos que notaram em situações do seu contexto social. De acordo com Vygotsky (2008, p.35):

\footnotetext{
(...) a brincadeira cria uma zona de desenvolvimento iminente na criança. Na brincadeira, a criança está sempre acima da média da sua idade, acima de seu comportamento cotidiano; na brincadeira, é como se a criança estivesse numa altura equivalente a uma cabeça acima da sua própria altura. A brincadeira em forma condensada contém em si, como na mágica de uma lente de aumento, todas as tendências do desenvolvimento; ela parece tentar dar um salto acima do seu comportamento comum.
}

Sendo assim, constata-se que a escola é um lugar em que a brincadeira é de suma importância para o desenvolvimento da criança, pois permite a construção do conhecimento através de práticas de ludicidade.

\section{CONSIDERAÇÕES FINAIS}

No breve histórico sobre o Currículo da Educação Infantil, inicialmente o foco era assistencialista, porém a partir das discussões da LDB imprimiu-se novas políticas públicas comprometidas com a organização do currículo para essa etapa da educação básica.

A partir dessa legislação e a legitimação da educação infantil como integrante da educação básica, a BNCC é promulgada com o intuito de retomar e fortalecer o conceito de criança como sujeito histórico e de direitos, que interage, brinca, imagina, fantasia, deseja, aprende, observa, experimenta, narra, questiona e constrói e assim baseado nesse conceito imprime-se as competências para a implementação curricular da base no território nacional.

As relações entre a BNCC e o direito de brincar na educação infantil incluem um repensar a prática docente. Esse planejamento docente tem que incluir brincadeiras que proporcionem o aprendizado das crianças. Para futuros trabalhos propõe a reflexão sobre um estudo de caso sobre implementação da BNCC na educação infantil em um município do território brasileiro.

\section{REFERÊNCIAS}

BRASIL. Lei de Diretrizes e Bases da Educação Nacional. Lei número 9394, 20 de dezembro de 1996. Brasília: MEC, 1996. Disponível em: http://portal.mec.gov.br/seesp/arquivos/pdf/lei9394_Idbn1.pdf. Acesso em: 20 abr. 2020.

BRASIL. Ministério da Educação. Base Nacional Comum Curricular. Brasília, DF: MEC, 2020. Disponível em: 
http://basenacionalcomum.mec.gov.br/images/BNCC_El_EF_110518_versaofinal_site.pdf. Acesso em: 10 abr. 2020.

BRASIL. Lei n 12.796, de 4 de abril de 2013. Altera a Lei no 9.394, de 20 de dezembro de 1996, que estabelece as diretrizes e bases da educação nacional, para dispor sobre a formação dos profissionais da educação e dar outras providências. Diário Oficial da União, Brasília, DF, 4 abr. 2013.

BRASIL. Ministério da Educação. Conselho Nacional de Educação Câmara de Educação Básica. Resolução n 5, de 17 de dezembro de 2009. Brasília: MEC, 2009. Disponível em: http://www.portalsas.com.br/portal/pdf/Resolucao_n5.pdf. Acesso em: 27 abr. 2020.

BRASIL. Ministério da Educação. Conselho Nacional de Educação Câmara de Educação Básica. Resolução n² de 22 de dezembro de 2017. Brasília: MEC, 2017. Disponível em: http://portal.mec.gov.br/index.php?option=com_ docman\&view=download\&alias=79631-rcp002-17-pdf\&category_slug=dezembro-2017-pdf\&Itemid=30192. Acesso em: 27 abr. 2020. 